\title{
Two active site divalent ions in the crystal structure of the hammerhead ribozyme bound to a transition state analog
}

Aamir Mir and Barbara L. Golden ${ }^{*}$

Department of Biochemistry, Purdue University, West Lafayette, IN 47907.

Supporting Information 


\section{Materials and Methods:}

\section{RNA Synthesis:}

The molecule described here was designed based on the previously crystallized RzB hammerhead ribozyme. ${ }^{1}$ The ribozyme was assembled from three pieces of RNA. The first piece of RNA is formally the ribozyme strand (green in Figure 1). The RNA that is formally the substrate strand and that would be cleaved if synthesized as a single RNA was divided into two fragments. The first fragment consists of the first 7 nucleotides of the substrate strand through and including $\mathrm{C} 17$. The second fragment was 13 nucleotides in length and first nucleotide of this fragment is U1.1. C17 has free 3'- and 5'-hydroxyl groups and U1.1 has a free 5'-hydroxyl. These are shown in pink in Figure 1. Thus, when the three strands are annealed, the phosphate group at the cleavage site is absent.

The ribozyme strand was synthesized by in vitro transcription as described previously. ${ }^{2}$ Briefly, a DNA template was designed which contained a T7 promoter, the ribozyme sequence of RzB and an Ear I restriction site. The DNA was then cloned into pUC-19 vector and amplified in DH5 $\alpha$ cells. Following plasmid purification and cleavage by Ear I, the DNA was used as a template for in vitro transcription using T7 RNA polymerase. The ribozyme strand was then purified using a PAGE gel. The two strands that contain nucleotides that would make up the substrate were purchased from Dharmacon (GE Life Sciences). They were deprotected and desalted according to manufacturer's guidelines prior to use.

RNA Crystallization:

The ribozyme was reconstituted by mixing $0.226 \mathrm{mM}$ of the ribozyme strand and $0.235 \mathrm{mM}$ of each substrate strand in $10 \mathrm{mM}$ potassium cacodylate $\mathrm{pH}$ 6.0. To ensure proper refolding of the transition state analog, the mixture was heated to $90{ }^{\circ} \mathrm{C}$ for $1 \mathrm{~min}$, and cooled to room temperature for $10 \mathrm{~min}$. Next $10 \mathrm{mM} \mathrm{MgCl}_{2}$ and $2 \mathrm{mM} \mathrm{NH}_{4} \mathrm{VO}_{3}$ were added to the mixture and the RNA was incubated at $50{ }^{\circ} \mathrm{C}$ for $5 \mathrm{~min}$. The mixture was cooled again for $10 \mathrm{~min}$ at room temperature prior to use.

To crystallize the RNA, a1 $\mu \mathrm{L}$ drop of the refolded ribozyme was mixed with a $1 \mu \mathrm{L}$ drop of the reservoir solution (32 \% 2-methyl-2,4-pentanediol, $0.9 \mathrm{M}$ potassium chloride, $50 \mathrm{mM}$ Tris-HCL $\mathrm{pH} 8.2,0.5 \mathrm{mM}$ spermine and $2 \mathrm{mM} \mathrm{NH}_{4} \mathrm{VO}_{3}$ ). These drops were equilibrated by vapor diffusion against $1 \mathrm{~mL}$ of reservoir solution. Crystals were obtained in about 4 weeks. Crystals were 
soaked in a cryostabilization buffer containing reservoir solution, $5 \%$ isopropanol and either 50 $\mathrm{mM}$ of $\mathrm{Mg}^{2+}$ or $10 \mathrm{mM} \mathrm{Mn}^{2+}$. These crystals were then flash cooled and stored in liquid nitrogen.

Crystal Structure Determination:

Data collection was performed at LS-CAT beamlines 21-ID-F and 21-ID-D at the Advanced Photon Source in Argonne national lab. Data was collected at $12.7 \mathrm{keV}$ and $8.26 \mathrm{keV}$ for crystals soaked in $\mathrm{Mg}^{2+}$ and $\mathrm{Mn}^{2+}$ respectively. Data were processed and indexed in HKL2000 in the space group $\mathrm{C}_{22} 22_{1}$. We used PHENIX ${ }^{3}$ for phase determination and refinement. The phase was determined using RzB WT structure (PDB id: 5DI2) as search model in Phaser-MR module provided in PHENIX. The successful MR solution had TFZ score of 14.4 and LLZ of 1341.133. The initial structure was then improved by several rounds of manual building in $\operatorname{Coot}^{4}$ and refinement in Phenix. 
TABLE S1. Data collection and refinement statistics.

\begin{tabular}{|c|c|c|}
\hline Data Collection & $\mathrm{Mg}^{2+}(\mathrm{pdbid}-5 \mathrm{EAO})$ & $\mathrm{Mn}^{2+}(\mathrm{pdbid}-5 \mathrm{EAQ})$ \\
\hline cell dimensions $(\AA)$ & $80.0,87.0,105$ & $81.3,87.4,106$ \\
\hline Wavelength $(\AA)$ & 0.979 & 1.501 \\
\hline Resolution $(\AA)$ & $50.0-3.00$ & $50.0-2.95$ \\
\hline (last shell) & $(3.05-3.00)$ & $(3.00-2.95)$ \\
\hline $\mathrm{R}_{\text {merge }}(\%)$ & $14.2(55.5)$ & $19.6(63.6)$ \\
\hline $1 / \sigma(I)$ & $51.6(5.7)$ & $139.7(19.4)$ \\
\hline no. of reflections & 14333 & 12773 \\
\hline redundancy & $12.5(12.6)$ & $6.3(5.0)$ \\
\hline completeness (\%) & $99.4(97.8)$ & $99.4(97.2)$ \\
\hline \multicolumn{3}{|l|}{ Refinement } \\
\hline Resolution $(\AA)$ & 28.3-3.00 & $27.4-3.20$ \\
\hline (last shell) & $(2.99-3.09)$ & $(3.35-3.20)$ \\
\hline no. of reflections & 14229 & 11834 \\
\hline no. of reflections in the test set & 1405 & 1180 \\
\hline $\mathrm{R}_{\text {work }} / \mathrm{R}_{\text {free }}(\%)$ & $22.7 / 26.9(30.4 / 35.3)$ & $24.6 / 28.6(28.6 / 35.9)$ \\
\hline \multicolumn{3}{|l|}{ (last shell) } \\
\hline \multicolumn{3}{|l|}{ no. of atoms } \\
\hline RNA & 1456 & 1456 \\
\hline ions & 8 & 7 \\
\hline average B-factor & 39.9 & 76.1 \\
\hline rmsd bond-lengths, $\AA$ & 0.006 & 0.007 \\
\hline RMSD bond angles, $^{\circ}$ & 1.154 & 1.488 \\
\hline Coordinate error $(\AA)$ & 0.34 & 0.36 \\
\hline
\end{tabular}



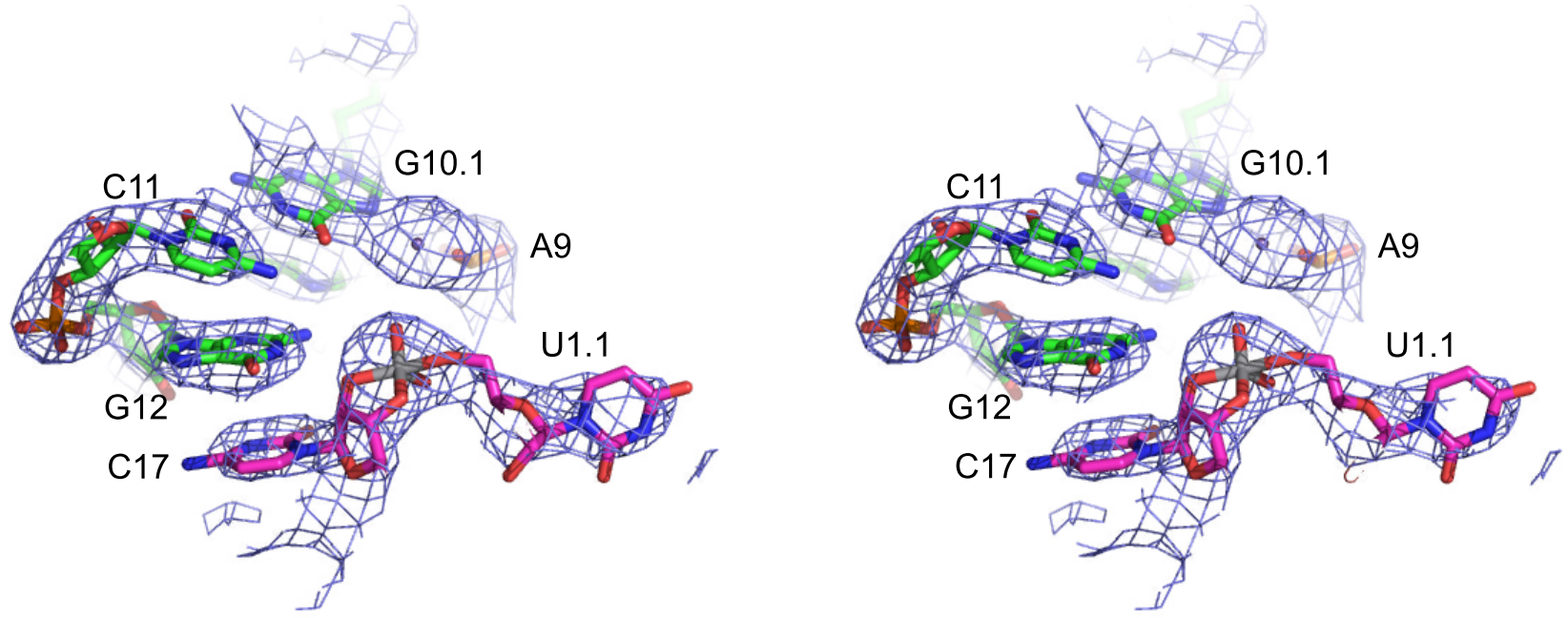

Figure S1. Electron density for the hammerhead ribozyme active site. Crystals of the hammerhead ribozyme bound to a transition state analog were grown in $\mathrm{Mg}^{2+}$ containing buffer and then soaked into a cryostabilization buffer containing $\mathrm{Mn}^{2+}$. The $2 \mathrm{~F}_{\mathrm{o}}-\mathrm{F}_{\mathrm{c}}$ map is shown contoured in blue at $1.5 \sigma$. For clarity in rendering the electron density map, this figure has been clipped and $\mathrm{Mn} 2$ is therefore not visible. The image is rendered as wall-eyed stereo using Pymol.
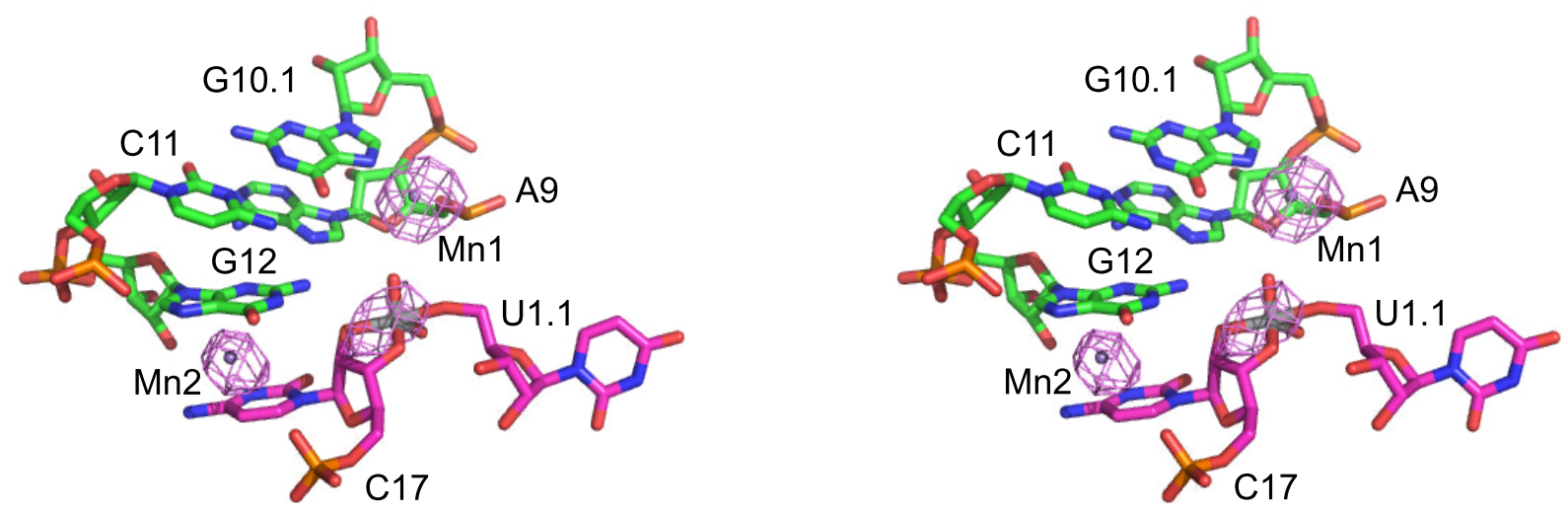

Figure S2. Anomalous diffraction from a $\mathrm{Mn}^{2+}$-soaked crystal. Crystals of the hammerhead ribozyme bound to a transition state analog were grown in $\mathrm{Mg}^{2+}$ containing buffer and then soaked into a cryostabilization buffer containing $\mathrm{Mn}^{2+}$. An anomalous diffraction map, contoured here at $3 \sigma$, was calculated to determine the positions of the $\mathrm{Mn}^{2+}$ ions and vanadate bound to the ribozyme. The image is rendered as wall-eyed stereo using Pymol. 

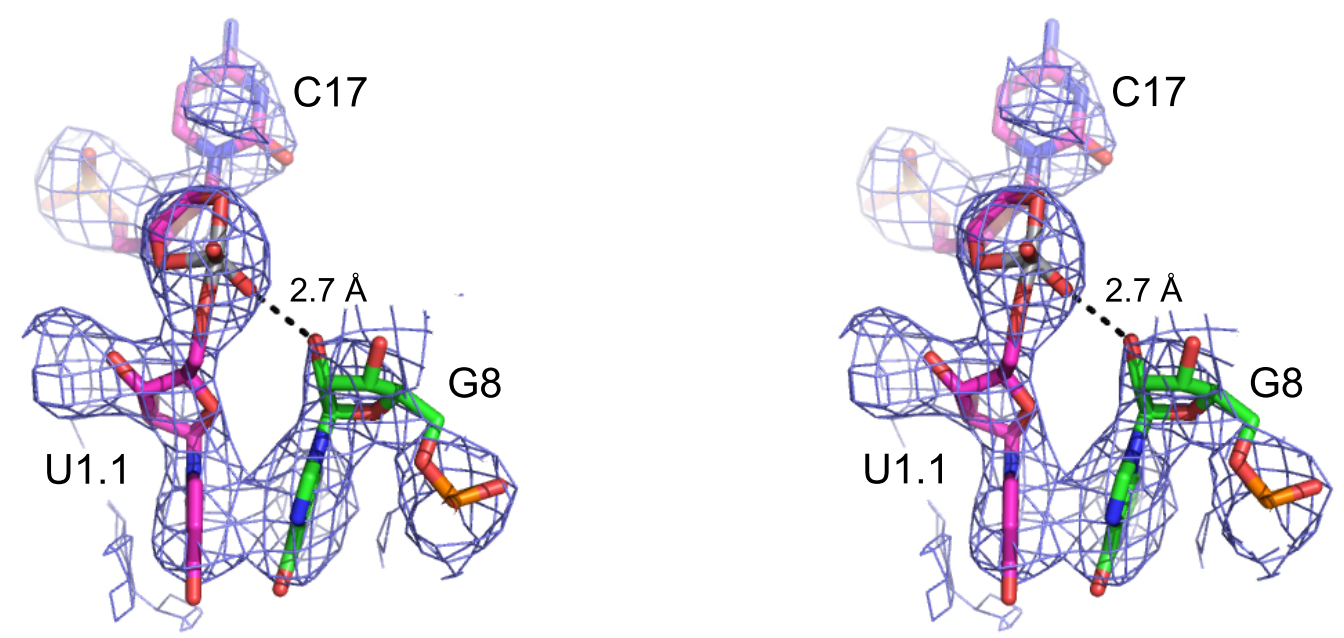

Figure S3. Electron density around G8. The $2 \mathrm{~F}_{\mathrm{o}}-\mathrm{F}_{\mathrm{c}}$ map is contoured at $1.2 \sigma$. The image is rendered as wall-eyed stereo using Pymol.

\section{Literature cited}

1. Mir, A., Chen, J., Robinson, K., Lendy, E., Goodman, J., Neau, D. B., and Golden, B. L. (2015) Two divalent metal ions and conformational changes play roles in the hammerhead ribozyme cleavage reaction, Biochemistry.

2. Golden, B. L. (2007) Preparation and crystallization of RNA, In Macromolecular Crystallography Protocols (Doublié, J. W. a. S., Ed.), pp 239-257, Humana Press.

3. Adams, P. D., Afonine, P. V., Bunkóczi, G., Chen, V. B., Davis, I. W., Echols, N., Headd, J. J., Hung, L. W., Kapral, G. J., Grosse-Kunstleve, R. W., McCoy, A. J., Moriarty, N. W., Oeffner, R., Read, R. J., Richardson, D. C., Richardson, J. S., Terwilliger, T. C., and Zwart, P. H. (2010) PHENIX: a comprehensive Python-based system for macromolecular structure solution, Acta Crystallogr D Biol Crystallogr 66, 213-221.

4. Emsley, P., Lohkamp, B., Scott, W. G., and Cowtan, K. (2010) Features and development of Coot, Acta Crystallogr D Biol Crystallogr 66, 486-501. 